\section{Should All Pharmacists Entering a Patient Care Setting Have Completed (at Least) a Canadian Hospital Pharmacy Residency Board-Accredited Residency?}

\section{THE "PRO" SIDE}

To begin, I think it would be appropriate for me to define the platform from which I will be establishing my argument. First, it's unfortunate that the question includes the word "hospital" (as part of the name of the residency board), because I feel that the name of the Board should have been changed a long time ago to the "Canadian Pharmacy Residency Board". Notably, the Canadian Hospital Pharmacy Residency Board no longer calls its accredited residency a "hospital residency". Rather, the term "pharmacy practice residency" has been used since 1996, because "contemporary pharmacy practice residencies are delivered in diverse practice settings. [Furthermore] pharmacy practice residencies develop leadership skills that can be applied to any position in any practice setting. " ${ }^{, 2}$ Second, I will be dealing only with the Canadian health care system, in which pharmacists can practise pharmaceutical care upon graduation with a Bachelor of Science (BSc) degree from an accredited school of pharmacy, provided they have met or completed the appropriate provincial licensing requirements. These types of graduates, with no additional postgraduate training, will always benefit from an accredited residency program. Finally, I have been in practice for over 30 years and have been mentoring and preceptoring students for a similar period of time.

In arguing the "pro" side, I will try to remind the reader of the educational continuum and the fact that the question is simply asking where we need to "draw the line in the sand" to establish the minimum standard for this professional function, to establish the fact that pharmacists should be practising effectively in all direct patient care arenas, to establish the importance of experiential learning in raising the competency level of BSc graduates, and to reinforce the fact that pharmacy practice residency programs are well positioned to achieve that increment in professional growth and development that is required to allow these practitioners to be effective direct patient care pharmacists.

The growth and development of any individual is an incremental process that begins at birth and ends at death. It may involve the formal educational process of going to grade school and high school and then undertaking undergraduate programs and/or various postgraduate programs. So what the question for this column is essentially asking is, what level of pharmacy training is minimally acceptable for a pharmacist to be "competent" at providing pharmaceutical care? ${ }^{3,4}$

For anyone who has done a residency or been involved in teaching, mentoring, or preceptoring graduates of an accredited entry-level professional BSc degree program in pharmacy, the answer to the question is clearly Yes! Graduates of these programs are generally weak at establishing a relationship with a patient or client. They are generally weak at gathering information about patients' health: the signs and symptoms of their current medical problems; their past medical problems; their current medications and whether those drugs are being taken as prescribed, producing benefits, or causing adverse effects; and the patients' characteristics, allergy status, relevant beliefs, and lifestyle factors pertaining to health. These graduates are generally weak at determining the patient's desired health outcomes and priorities. They are generally weak at determining if the patient has any drug-related problems, the significance of those problems, and their relative priority. They are generally weak at formulating optimal care plans for their patients. They are generally unable to systematically and critically evaluate the various therapeutic options that may be appropriate for their patients and are usually unable to communicate these therapeutic options to patients in a manner that promotes understanding. They are usually weak at responding to patients' concerns and questions and accurately presenting referral information to patients in a timely manner. They are usually weak at confirming therapeutic objectives with patients. The provision of nondrug and drug information to the patient to support the care plan is usually incomplete, missing essential, relevant components. They are usually very weak at obtaining and evaluating information about the patient's progress with the care plan, perhaps assuming that the job is complete once the care plan has been stated. If the status of the patient should change, they are usually weak at systematically considering the options effectively and modifying the care plan as needed. They are always weak at documenting in the patient's health record their findings, follow-ups, recommendations, information provided, and outcomes. If they do attempt to document in the chart, essential supporting information is frequently missing; and the information provided is never formatted consistently enough to allow for efficient retrieval.

This is not to say that entry-level professional BSc degree programs in pharmacy are weak. That would be like saying that high schools are offering weak programs in the overall educational process. On the contrary, entry-level professional BSc degree programs in pharmacy prepare pharmacists to perform a certain level of service in any setting. ${ }^{2,5-10}$ The question is whether that level of minimal competence is adequate to achieve the current standards of practice in direct patient care called for by the colleges of pharmacy in this land.

One of the major changes in Canadian pharmacy over the past 2 decades has been the gradual shift from pharmacists functioning mostly as dispensers of medications to their having increased involvement in effective patient care. Moreover, soul searching within the profession has focused on the development of the concept and practice of pharmaceutical care by community, long-term care, and hospital pharmacists, particularly as health economics dictate a trend toward outpatient and ambulatory care. The borders between community and hospital practice have 
blurred as institutions strive to get patients back into the community where they can receive home-based care. ${ }^{2}$ The result has been greater emphasis on patient care and a greater role for pharmacists (no matter where they practise) in identifying, solving, and preventing drug-related problems. The Fraser Health Authority has been a leader in translating this trend into practice in the community, as it employs several pharmacists who work exclusively in the community setting, trying to keep patients out of hospital. ${ }^{11}$

Professional knowledge cannot be characterized in a manner that is independent of how it is learned and how it is used. It is through looking at the contexts of its acquisition and its use that its essential nature is revealed. ${ }^{\text {? }}$

Numerous adult educators have underscored the fundamental role that experience plays in learning in adulthood. ${ }^{12-17}$ One of Lindeman's ${ }^{12} 4$ major assumptions about adult learning was that "the resource of highest value in adult education is the learner's experience." Experience then becomes "the adult learner's living textbook ... already there waiting to be appropriated". Similarly, one of the major assumptions underlying Knowles's ${ }^{13}$ work on andragogy was that adults "accumulate an increasing reservoir of experience that becomes an increasingly rich resource for learning." As adults practise longer, they accumulate both a greater volume and a greater range of experiences. Knowles also observed that adults tend to define themselves by their experiences, describing themselves as parents, spouses, emergency medicine pharmacists, and so on. Usher and others $^{14}$ and Boud and Miller ${ }^{15}$ also acknowledged that experience was foundational to adult learning, advocating that adults use their experience, but with a clear understanding that this form of knowledge is highly influenced by the context. Brookfield" ${ }^{17}$ stated that "adults learn best when they feel the need to learn and when they have a sense of responsibility for what, why and how they learn ... so the learning content and process must bear a perceived and meaningful relationship to past experiences. What is to be learned is to be related to the individual's developmental changes and life tasks."

The pharmacy practice residency program is currently well placed to identify the shortcomings of BSc graduates in pharmacy and to take them incrementally to the next higher, more effective level of competency in direct patient care. The stated purpose of a pharmacy practice residency program is to refine professional competence in direct patient care (through supervised practice under the guidance of model practitioners), pharmacy operational services, and project management gained during study in an accredited pharmacy professional degree program; to refine personal practice skills; and to develop leadership skills that can be applied in any position and in any practice setting. The educational outcomes of a pharmacy practice residency include, at a minimum, providing evidence-based direct patient care as a member of interprofessional teams, managing and improving the medication-use process, exercising leadership, exhibiting skill in managing one's own practice of pharmacy, providing medication- and practice-related education, and demonstrating project management skills. ${ }^{1}$
So, should all pharmacists (with no further training beyond their BSc degree) entering a patient care setting have a Canadian Hospital Pharmacy Residency Board-accredited residency? My answer is unequivocally Yes!

\section{References}

1. Canadian Hospital Pharmacy Residency Board. Accreditation standards January 2010. Ottawa (ON): Canadian Society of Hospital Pharmacists; 2009 [cited 2009 Nov 11]. Available from: www.cshp.ca/programs/ residencyTraining/CHPRB_Standards_2010_-_FINAL.pdf

2. Woloschuk DMM. Is a 1 -year residency program long enough to prepare hospital pharmacists for practice? The "pro" side. Can J Hosp Pharm 2009;62(1):43-44.

3. Pharmaceutical care: information paper. Ottawa $(\mathrm{ON})$ : Canadian Society of Hospital Pharmacists; 2004 [cited 2009 Nov 11]. Available from: www.cshp.ca/dms/dmsView/1_IP_Pharmaceutical_Care_2004. pdf. Membership required to access content.

4. Framework of professional practice. Vancouver (BC): College of Pharmacists of British Columbia; 2006 [cited 2009 Nov 11]. Available from: www.bcpharmacists.org/library/D-Legislation_Standards/ D-2_Provincial_Legislation/1009-FPP.pdf

5. Martinusen D, Shalansky S. Pharmaceutical care: the new direction of hospital pharmacy. B C Health Manag Rev 1993 Spring/Summer:11-13.

6. Strand LM, Morley PC, Cipolle RJ, Ramsey R, Lamsam GD. Drug-related problems: their structure and function. DICP 1990; 24(11):1093-1097.

7. Association of Faculties of Pharmacy of Canada, Advisory Committee on Curricular Change. Appendix 1. Development of levels and ranges of educational outcomes expected of baccalaureate graduates. Vancouver (BC): The Association; 1999 [cited 2008 Nov 11]. Available from: www.afpc.info/downloads/1/Educational_Outcomes_1999.pdf

8. Francke DE. Levels of pharmacy practice. Drug Intell Clin Pharm 1976;10(9):534-535.

9. Eraut M. Developing professional knowledge and competence. London (UK): Falmer Press; 1994

10. Campagna KD. Pharmacists' levels of performance in making drug therapy decisions. Am J Health Syst Pharm 1995;52(6):640-645.

11. Fayerman P. Pharmacists' home visits help patients with meds: innovative program helping seniors is unique in Canada. Vancouver Sun: 2006 Jan 25 [cited 2009 Nov 11]. Available from: www.canada.com/ vancouversun/news/westcoastnews/story.html?id=2fda9a29-649b4eec-a023-e4f9ee458df1\&k=36561

12. Lindeman EC. The meaning of adult education. Michigan: Harvest House Publishers; 1961.

13. Knowles MS. The modern practice of adult education: from andragogy to pedagogy. Englewood Cliffs (NJ): Cambridge Adult Education; 1980.

14. Usher R, Bryant I, Johnston R. Adult education and the post-modern challenge. London (UK): Routledge; 1997.

15. Boud D, Miller N. Animating learning from experience. In: Boud D, Miller N, editors. Working with experience. London (UK): Routledge; 1996.

16. Angaran DM. The experts. Drug Intell Clin Pharm 1976;10:304.

17. Brookfield S. Understanding and facilitating adult learning. A comprehensive analysis of principles and effective practices. San Francisco (CA); Jossey-Bass Publishers; 1986.

Edward C Dillon, BA, BSC, BScPharm, ACPR, PharmD

Student Education and Residency Coordinator

Department of Pharmacy

Fraser Health Authority

Clinical Professor

Faculty of Pharmaceutical Sciences

University of British Columbia

Vancouver, British Columbia

Emergency Department

Royal Columbian Hospital

New Westminster, British Columbia 


\section{THE "CON" SIDE}

All professions must continually strive to improve the quality of services or care provided to patients and clients by their members. That principle is a foundation of continuous quality improvement strategies and has been embraced by the profession of pharmacy, in all its sectors, for many years. Because pharmacy practice residency programs are by definition designed to train pharmacists to improve patient care and drug therapy outcomes at a higher level of proficiency than those without such training, it is difficult to argue against the philosophical premise behind the "pro" position in this debate.

In this counterpoint, therefore, I will not attempt to discredit efforts by the profession to train pharmacists to be more highly competent practitioners, but will simply pose 2 challenge questions: (1) If pharmacists are to make a more meaningful contribution to the health care system, will added formal training be the principal solution to move the profession toward that goal? (2) Is a residency-type program the most effective way for the profession to ensure that the health care system has more competent or appropriately skilled pharmacists? The ordering of these questions is important, as discussions in favour of residencies often fail to examine other factors that may be more relevant to resolving the profession's underachieving performance in the delivery of meaningful patient care.

Both the "Moving Forward" human resources study of pharmacy in Canada" and the "Blueprint for Pharmacy" vision for pharmacy in Canada ${ }^{2}$ referred to the importance of education and training that will ensure that pharmacists are capable of working in new practice models. However, the Blueprint also identified a number of other factors that must be part of any resolution strategy to ensure that patients receive consistent quality care from pharmacists.

Indeed, there are several significant hurdles that the profession needs to address, and I will argue that until an integrated approach involving at least 3 other critical factors (i.e., in addition to education and training) is embraced by all sectors of the profession, we are unlikely to see meaningful change to raise the standard of care delivered by pharmacists, even if mandatory residency requirements are introduced. These 3 factors are practice regulation, reimbursement models, and the practice environment.

\section{Practice Regulation}

What is accepted as contemporary pharmacy practice is largely defined by provincial legislation. Pharmacy practice acts and bylaws set the requirements for registration as a pharmacist and the conditions under which practice is regulated to protect the public. The expectation of Canada's provincial ministries of health regarding the pharmacist's public protection role, however, is surprisingly one-dimensional. Pharmacists are principally expected to perform various functions associated with the control and safe distribution of scheduled drugs pursuant to the order of an authorized prescriber.

While our regulatory authorities have made pronouncements declaring pharmacists' responsibility to "manage drug therapy" or ensure "optimal patient outcomes", there is little evidence that provincial ministries of health have demanded that level of accountability by pharmacists in legislation and enforcement.

This superficial expectation leads to predictable results. First, what is seen to be the accepted norm for practice is largely measured against indicators of dispensing quality. In addition, almost all disciplinary proceedings against pharmacists involve incidents such as dispensing a drug without a valid prescription, patterns of inaccurate dispensing, fraudulent billing claims, or criminal or drug dependency behaviours. Furthermore, there is an absence of any real accountability on the part of pharmacists to investigate or intervene to resolve preventable drug misadventures (including nonadherance by patients). Finally, there is a profession-wide and societal tolerance of huge variability in the scope, depth, and quality of pharmacists' service across practice settings (including that in hospitals), once basic technical dispensing functions have been correctly performed.

The profession, including our regulatory authorities, has developed numerous statements of "standards of practice", but these typically represent articles of voluntary compliance that pharmacists are encouraged to adopt in practice. ${ }^{3}$ The profession lacks a universally accepted and universally followed minimal "standard of care" that (beyond the dispensing act) is provided at each patient encounter in all practice settings. Until the profession is ready to enforce a meaningful standard of care on all pharmacists under current educational requirements, added training through residencies is not likely to change prevailing practice patterns.

\section{Reimbursement Models}

It is not surprising, particularly for community pharmacy, that the value of pharmacists' contribution to the health care system is largely defined by the prescription-dispensing activity, since that is the principal manner through which pharmacists are rewarded for their professional service. While some pharmacists may be driven by altruistic or personal practice enrichment motives, there simply is little incentive for most pharmacists to provide a different style of care to patients.

Indeed, from a business perspective, significant disincentives exist to the pharmacist being compensated for "managing drug therapy" when that activity does not include dispensing a prescription. For many years, public drug plans, third-party insurers, and cash-paying patients have been clearly uninterested in any health care contribution made by pharmacists to patients, beyond prescription services.

Some payers have recently shown more willingness to consider alternative reimbursement methods that could reward the pharmacist for clinical interventions. And, interestingly, some segments of the profession are now expressing skepticism that a profitable business model for pharmacy built around clinical service fees can replace or compensate for loss of current revenues from dispensing fees without significant disruption of traditional retail pharmacy operations.

However, if the health care system is prepared to provide incentives to pharmacists for substantive care interventions, many pharmacists will venture into these new business models and are not likely to require further residency training to competently provide this care. 
The regulatory framework for pharmacy should set the bar for a required standard of actual and meaningful care by all pharmacists that is appropriately higher than simply regulating unsafe care. The reimbursement system should then create incentives and appropriate rewards for pharmacists for practice behaviour that utilizes the fullest extent of the pharmacist's current level of training in activities intended to enhance the quality of medication therapy in patients.

\section{Practice Environment}

How pharmacists engage patients in meaningful clinical exchanges is significantly influenced by the practice environment. Management policies, procedures, and expectations; the physical facilities; appropriate safeguards for privacy and confidentiality; health records and information technology; workload levels; the climate for interprofessional collaboration; standardized protocols for direct patient care; and appropriately aligned patient expectations are all required to contribute to a supportive setting for direct patient care by pharmacists.

Even highly trained pharmacists working in hospital pharmacy departments will struggle in their efforts to provide quality patient care if the practice setting environment is deficient. Although some pharmacists may be able to work around some features of a substandard environment, mediocrity and lack of commitment to the duties associated with managing medication therapy frequently become evident if the environment is not conducive to quality care.

\section{Mandatory Residency Training Requirements for Patient Care?}

After the above 3 factors have been adequately addressed, it may then be reasonable to consider the need for additional training for pharmacists. What will be necessary, however, is a clearer articulation of the actual knowledge deficiency or skill deficit that will be repaired by residency training, the rectification of which will lead to more highly functioning pharmacists in patient care.

Our current perspective on the beneficial post-training effects of residencies is based on a very selective sampling - most residents begin their careers as pharmacists in highly supportive hospital practice environments and many continue in these settings for their entire careers. Those whose careers take them out of the hospital may retain a commitment to comprehensive patient care for a period of time but will eventually adopt a pattern of practice that is consistent with what is expected in the new practice setting.

If additional "learning and supervised practice" time were the solution to ensuring that pharmacists perform at a higher level in patient care duties, are there alternatives to formal residency training? Provincial entry-to-practice requirements across Canada are not standardized. After completing a university program in pharmacy, structured internship requirements vary from zero hours (in British Columbia) to 12 weeks (in Ontario). Perhaps we should encourage all provinces to introduce a panCanadian standardized postdegree internship training period. Could an expanded internship system solve the knowledge and skill deficits of new pharmacists? Probably not, as the training quality of internships is still quite variable, even with close regulatory authority control.

The capacity of training sites to absorb approximately 1200 Canadian pharmacy graduates into residency programs each year is clearly a rate-limiting reality. Even if a portion of these graduates do not intend to move into a patient care role, the numbers of residency positions that would be needed greatly exceeds the 40 to 50 residency spots available now in Canada. A more realistic approach would be to re-evaluate the educational outcomes of the current undergraduate curriculum in pharmacy and to enhance the clinical training objectives of the professional program. Discussions at several pharmacy schools in Canada to introduce a doctor of pharmacy curriculum as the first professional degree in pharmacy are attempting to specifically address this issue.

In summary, a requirement that all pharmacists complete a residency before entering patient care settings would seem to be the answer to ensure that pharmacists deliver effective patient care. However, other factors such as practice regulation, reimbursement, and the nature of the practice environment must be addressed in an integrated manner to substantively improve pharmacy's inconsistent performance in the management of drug therapy. Educational strategies that involve improvements to the undergraduate pharmacy program are probably more realistically feasible at this time relative to the substantial resources that would be required to introduce over 1000 residency training positions.

References

1. Management Committee. Moving forward: pharmacy human resources for the future. Final report. Ottawa (ON); Canadian Pharmacists Association; 2008.

2. Task Force on a Blueprint for Pharmacy. Blueprint for pharmacy: the vision for pharmacy. Ottawa $(\mathrm{ON})$ : Canadian Pharmacists Association; 2008.

3. Model standards of practice for Canadian pharmacists. Ottawa (ON): National Association of Pharmacy Regulatory Authorities; 2009 Mar.

David Hill, EdD, FCSHP

College of Pharmacy and Nutrition

University of Saskatchewan

Saskatoon, Saskatchewan

\section{Disclaimer}

The opinions expressed in this article do not necessarily reflect the personal views of the author and should not be interpreted to represent the official position of the University of Saskatchewan College of Pharmacy and Nutrition, the Saskatchewan College of Pharmacists, or the Canadian Council for Accreditation of Pharmacy Programs. 